\title{
Induction of potent protection against acute and latent herpes simplex virus infection in mice vaccinated with dendritic cells
}

\author{
MEHDI GHASEMI ${ }^{1}$, MURAT ERTURK $^{1}$, KURTULUS BURUK $^{1}$ \& MEHMET SONMEZ ${ }^{2}$ \\ ${ }^{1}$ Medical Microbiology and ${ }^{2}$ Hematology Departments, Medical School, Karadeniz Technical University, \\ Trabzon, Turkey
}

\begin{abstract}
Background aims. Dendritic cells (DCs) are the most potent antigen presenting cells of the immune system and have been under intense study with regard to their use in immunotherapy against cancer and infectious disease agents. In the present study, DCs were employed to assess their value in protection against live virus challenge in an experimental model using lethal and latent herpes simplex virus (HSV) infection in Balb/c mice. Methods. DCs obtained ex vivo in the presence of granulocyte-macrophage colony-stimulating factor and interleukin-4 were loaded with HSV-1 proteins (DC/HSV-1 vaccine). Groups of mice were vaccinated twice, 7 days apart, via subcutaneous, intraperitoneal or intramuscular routes with DC/HSV-1 and with mock (DC without virus protein) and positive (alum adjuvanted HSV-1 proteins [HSV-1/ALH]) control vaccines. After measuring anti-HSV-1 antibody levels in blood samples, mice were given live HSV-1 intraperitoneally or via ear pinna to assess the protection level of the vaccines with respect to lethal or latent infection challenge. Results. Intramuscular, but not subcutaneous or intraperitoneal, administration of DC/HSV-1 vaccine provided complete protection against lethal challenge and establishment of latent infection as assessed by death and virus recovery from the trigeminal ganglia. It was also shown that the immunity was not associated with antibody production because DC/HSV-1 vaccine, as opposed to HSV-1/ALH vaccine, produced very little, if any, HSV-1-specific antibody. Conclusions. Overall, our results may have some impact on the design of vaccines against genital HSV as well as chronic viral infections such as hepatitis B virus, hepatitis $\mathrm{C}$ virus and human immunodeficiency virus.
\end{abstract}

Key Words: dendritic cells, herpes simplex virus, mice, vaccine

\section{Introduction}

Dendritic cells (DCs) are known as the most potent cells with respect to capturing and processing of antigens and have been the subject of intense interest in generating unique immune responses against tumor antigens, a treatment modality known as cancer or tumor vaccines (1). This treatment modality for cancer patients is based on a vaccine formulation generated ex vivo by first differentiating autologous monocytes into immature DCs (iDCs) in the presence of cytokines (granulocyte-macrophage colony-stimulating factor [GM-CSF] and interleukin [IL]-4) and then loading them with tumor tissue lysates or tumor-specific antigens to prepare so-called tumor antigen-loaded mature DCs (mDCs) for clinical use. The use of vast numbers of such formulations has suggested that tumor antigen-loaded DCs may provide tumor eradication in experimental and clinical settings (1-3). However, numerous issues with regard to the methods of preparation and use of DC vaccines have not yet been optimized. These issues include the determination of the source of the DCs, the selection of the target antigens and their loading technique, and the route and number of injections $(4,5)$.

Despite several uncertainties with regard to preparing DC vaccines, a similar strategy in parallel with anti-cancer studies has been contemplated for diseases caused by microorganisms $(6,7)$. The first sample of a DC vaccine against infectious agents was for the treatment of Borrelia burgdorferi spirochete infection in experimental animals (8). DC vaccines subsequently were studied in various other experimental viral and non-viral infection models, including lymphocytic choriomeningitis virus, herpes simplex virus (HSV) type 2 and influenza virus (9-11) as well as bacterial, fungal and parasitic pathogens (12-15). Despite the vast heterogeneity of the microorganisms used, antigen-loaded DCs were highly competent in inducing both humoral and $\mathrm{T}$ cell-mediated responses. Consequently, DC-based vaccination has emerged as a promising tool to augment immune 
responses in persistent infections caused by viruses such as hepatitis B virus (HBV), hepatitis C virus (HCV) and human immunodeficiency virus (HIV) in experimental and clinical settings $(16,17)$. DCbased vaccination was reported to be safe and feasible and showed evidence of immunogenicity in HIV-1-positive individuals $(16,18-20)$. In the case of $\mathrm{HCV}$ infection, in which it is thought that the virus impairs DC maturation and functions, it was proposed that DCs loaded and matured ex vivo with HCV proteins could prime naïve T cells or stimulate existing HCV-specific cellular immunity or both $(21,22)$. In a more recent study, DCs loaded with recombinant $\mathrm{HCV}$ core proteins and peptides provided strong humoral and cellular response (23). Another study showed that DCs transfected with adenovirus having HCV NS3 protein genes elicited $\mathrm{CD} 4^{+} \mathrm{T}_{\mathrm{H}} 1$ and $\mathrm{CD} 8^{+} \mathrm{T}$-cell responses in different mouse species (24). A situation similar to HCV holds true for HBV, for which insufficient specific cell response is thought to be responsible for persistence of the virus $(25,26)$. It was reported that autologous DCs loaded with hepatitis B virus surface antigen (HBsAg) were safe and able to induce anti-HBs response in phase I clinical studies performed on healthy volunteers (27). Another study showed that patients with chronic HBV infection who had received HBsAg-loaded DCs had repressed HBV replication and decreased viral load in serum, developed anti-HBV antibody and lost HBeAg (28). Further studies demonstrated that insufficient DC activity in hepatitis patients could be restored by DC vaccine loaded with $\mathrm{HBcAg}$ and $\mathrm{HBsAg}$ and that autologous T-lymphocyte proliferation and antigenspecific interferon (IFN) $\gamma$ production could be increased (29). Vaccination of patients with HBVrelated hepatocellular carcinoma with $\mathrm{HBcAg}$ - and HBsAg-loaded DCs induced co-stimulatory molecule synthesis (CD40, CD80 and CD86) and stimulated autologous $\mathrm{T}$-cell proliferation and IFN- $\gamma$ secretion, suggesting that a DC vaccine could be promising for the treatment of HBV-based liver cancers (30).

Animal models for the development and evaluation of DC-based vaccines against chronic and latent viral infections are limited. The most appropriate animal models to study the features of a latent viral infection are HSV guinea pig/mouse models described previously $(29,31)$. The problems of DC vaccine preparations discussed in the field of cancer immunotherapy are also valid for infectious diseases. Using the well-established HSV-mouse model $(29,31)$, we set out to optimize some parameters including the route of injection to obtain a better immune response against active and latent viral infections by employing DC vaccines.

\section{Methods}

\section{Cell and virus strains}

The Wall and F strains of HSV-1 were propagated and titrated in Vero cells (Vircell, Granada, Spain) as described previously (32) using minimal essential medium (MEM) supplied with $2 \%$ fetal bovine serum (FBS). Briefly, the infected cells were collected and subjected to freeze and thaw cycles twice. After centrifugation, the cell-free supernatant was harvested and stored at $-80^{\circ} \mathrm{C}$ as a stock virus pool. The titer was determined by plaque assay using Vero cells grown to confluence in 24 -well plates. The wells were infected with viral serial dilutions $\left(10^{-1}-10^{-8}\right)$ in duplicates. After incubation at $37^{\circ} \mathrm{C}$ in $5 \%$ carbon dioxide $\left(\mathrm{CO}_{2}\right)$ for $1 \mathrm{~h}$, the inoculum was removed, and plaque overlay medium (double-strength MEM and 1.6\% carboxymethylcellulose mixed $1: 1$ ) was added to each well. After incubation for $72 \mathrm{~h}$, plates were rinsed and stained, and the plaques were counted. Plaque titers (plaque-forming units $/ \mathrm{mL}$ ) were calculated directly from the dilution factor. Median lethal dose of the stock virus was determined in Balb/c mice $6-8$ weeks old infected with 10 -fold virus dilutions $\left(10^{-2}-10^{-7}\right)$ by the intraperitoneal route as described (32).

\section{$H S V-1$ protein preparation}

HSV-1 proteins were prepared by propagation of HSV$1 \mathrm{~F}$ strain in Vero cells and subsequent zwitterionic detergent extraction by using Empigen (Albright \& Wilson, Hull, UK) as described elsewhere (32). Briefly, HSV-1-infected Vero cells showing $80-90 \%$ cytopathic effect were harvested and pelleted by centrifugation. The pellets were rinsed twice with cold phosphate-buffered saline (PBS) and re-suspended in $2.5 \%$ Empigen in PBS. Following sonication, insoluble material was removed by high-speed centrifugation $(32,000 \mathrm{rpm}$ for $1 \mathrm{~h})$, and the resulting detergent-protein extract was dialyzed against PBS. A mock infected Vero cell protein extract (crude extract) was also prepared in parallel for use as a virus negative control antigen source. For partial purification, both types of extracts were subjected to centrifugation $(26,000 \mathrm{rpm}$ for $5 \mathrm{~h}$ ) on a $20 \%$ sucrose cushion. The partially purified virus protein mixture contains the four major HSV-1 glycoproteins, $\mathrm{gB}, \mathrm{gC}, \mathrm{gD}$ and $\mathrm{gE}$, and several other viral and non-viral proteins (32). After determination of the total protein content by the modified Lowry method, the HSV-1 and mock antigen preparations were stored at $-80^{\circ} \mathrm{C}$ until use.

\section{Generation of DCs}

Bone marrow-derived DCs were obtained from $\mathrm{Balb} / \mathrm{c}$ mice as described earlier (33) with some 
modifications. Femora and tibiae of Balb/c mice 8-12 weeks old were flushed with RPMI medium, and red blood cells were subsequently lysed using ammonium chloride. Cells $\left(1 \times 10^{6}\right.$ cells $\left./ \mathrm{mL}\right)$ were cultured in 24-well plates in complete RPMI medium supplemented with $20 \mathrm{ng} / \mathrm{mL}$ each of recombinant mouse GM-CSF and IL-4 (PeproTech, London, UK), 5\% FBS, $50 \mu M$ 2-mercaptoethanol and penicillin/streptomycin $(100 \mu \mathrm{g} / \mathrm{U} / \mathrm{mL})$. After 6 days of culture at $37^{\circ} \mathrm{C}$ in $5 \% \mathrm{CO}_{2}$, with two changes of the medium on day 2 and day 4, semi-adherent and non-adherent cells were harvested by pipetting and used as iDCs for pulsing with the HSV-1 proteins as described subsequently. For the maturation of DCs (mDCs) before use in vaccination studies, antigen-loaded iDCs were cultured further for $24 \mathrm{~h}$ at $37^{\circ} \mathrm{C}$ in $5 \% \mathrm{CO}_{2}$ in $\mathrm{RPMI}$ medium supplemented with recombinant mouse TNF- $\alpha(20 \mathrm{ng} / \mathrm{mL})$.

\section{Flow cytometry analysis of DCs}

Immunophenotyping of iDCs and mDCs was performed by flow cytometry (Coulter Epics XL-MCL; Beckman Coulter, Miami, FL, USA). For each sample, $5 \times 10^{5}$ cells were stained with specific antibodies for $30 \mathrm{~min}$ at $4^{\circ} \mathrm{C}$ in $20 \mu \mathrm{L}$ of PBS containing $2 \%$ bovine serum albumin and $0.1 \%$ sodium azide, after pre-incubation of cells with Mouse BD Fc Block (2.4G2 clone; BD Biosciences, Istanbul, Turkey). The following fluorescein isothiocyanate (FITC)- or phycoerythrin (PE)-labeled monoclonal antibodies were used: hamster anti-mouse CD11c (HL3 clone), rat anti-mouse CD45R/B220 (RA3-6B2 clone), rat anti-mouse CD4 (GK1.5 clone), rat anti-mouse CD8a (53-6.7 clone), mouse anti-mouse I-A[d] (AMS-32.1 clone), rat anti-mouse CD40 (3/23 clone), hamster anti-mouse CD80 (16-10A1 clone) and rat anti-mouse CD86 (GL1 clone). As negative controls, FITC- or PE-labeled species- and isotypematched antibodies were used: hamster $\operatorname{Ig} 1-\lambda 1$ (G235-2356 clone), IgG2a-k/ $\lambda 1$ (R35-95 clone), IgG2b-k/ $\lambda 1$ (A95-1 clone), IgG2b-k/ $\lambda 1$ (MPC-11 clone) and IgG2-k $\lambda 1$ (B81-3 clone). All antibodies were purchased from BD Biosciences Pharmingen (San Diego, CA, USA). Data were analyzed using Expo32 analysis software (Beckman Coulter).

\section{Loading of DCs with HSV-1 proteins and vaccination of mice}

To prepare HSV-1 antigen-loaded DC vaccine (DC/ HSV-1), $1 \times 10^{6}$ iDCs obtained after 6 days of culture as described earlier were incubated with $50 \mu \mathrm{g}$ of HSV1 antigen mixture or control preparation at $37^{\circ} \mathrm{C}$ in $5 \% \mathrm{CO}_{2}$ for $3 \mathrm{~h}$. The cells were rinsed with RPMI medium three times, re-suspended in RPMI medium supplemented with $20 \mathrm{ng} / \mathrm{mL}$ of recombinant mouse TNF- $\alpha$, and incubated overnight as before to obtain mDCs. On day 7 , the cells were rinsed as just described and adjusted to $1 \times 10^{6} / \mathrm{mL}$. Via intraperitoneal, subcutaneous or intramuscular routes, $0.1 \mathrm{~mL}$ of this suspension was administered into groups of Balb/c mice in two dosages, 7 days apart. Two control groups were vaccinated subcutaneously with (i) mock antigenloaded DCs prepared in a similar way to DC/HSV-1 and (ii) alum-adjuvanted $\mathrm{HSV}-1$ vaccine (HSV-1/ ALH), which was prepared on the day before administration by mixing a predetermined quantity of HSV-1 antigen mixture with an equal volume of $\mathrm{ALH}$ (Superfos, Randers, Denmark). HSV-1/ALH given subcutaneously at $20 \mu \mathrm{g} / 0.1 \mathrm{~mL}$ per mouse served as a positive control because it is known to elicit virusspecific antibody response and protection against challenge with live HSV-1 (29).

\section{Measurement of antibody responses}

Anti-HSV-1 antibody levels in mice vaccinated with $\mathrm{DC} / \mathrm{HSV}-1$ or with control vaccines were assessed by enzyme-linked immunosorbent assay (ELISA) using serum samples obtained intra-cardially 7 days after the second injection as described (31). ELISA plates (Costar, High Wycombe/Buckinghamshire, UK) were coated with $100 \mu \mathrm{L}(2.5 \mu \mathrm{g}$ total protein) of HSV-1 antigen solution and incubated overnight at $4^{\circ} \mathrm{C}$. After a wash with PBS/Tween (Sigma-Aldrich, Ankara, Turkey), $100 \mu \mathrm{L}$ of test serum diluted 1:100 in $\mathrm{PBS} /$ Tween/bovine serum albumin was added and allowed to bind for $1 \mathrm{~h}$ at $37^{\circ} \mathrm{C}$. Plates were washed again, and horseradish peroxidase-conjugated antimouse IgG (Dako, Izmir, Turkey) was added to each well at a dilution of 1:1000. Plates were incubated and washed as before. Finally, $100 \mu \mathrm{l}$ of $p$-phenylenediamine dihydrochloride substrate in citrate phosphate buffer was added to the wells for $15 \mathrm{~min}$ to allow color development. The reaction was stopped by the addition of $2 \mathrm{~mol} / \mathrm{L}$ sulfuric acid, and absorbance values were read at $492 \mathrm{~nm}$. Sera from non-vaccinated healthy mice were used as negative controls, and sera obtained from mice successively injected with sublethal dosages of live HSV-1 were used as positive controls. ELISA titer was calculated by (test optical density [OD] - negative serum OD)/(positive serum $\mathrm{OD}-$ negative serum OD) $\times$ dilution of serum, and the results were given as $\log _{2}$ ELISA unit.

\section{Acute and latent HSV-1 infection of mice vaccinated with $D C$ vaccine}

To assess the protective power of DC/HSV-1 vaccine against acute or latent infection, the mice vaccinated 7 days apart with two doses of $\mathrm{DC} / \mathrm{HSV}-1$ or control 
vaccines were challenged in two different ways: (i) For the acute infection model, different groups of mice vaccinated via the subcutaneous, intraperitoneal, or intramuscular route were challenged with intraperitoneal injection of $5 \times$ median lethal dose of live HSV-1 (Wall strain) known to cause severe acute infection resulting in $100 \%$ death of mice within 2 weeks (31). (ii) For the latent infection model, mice vaccinated via the intramuscular route were challenged via the ear scarification method as described elsewhere (34,35). Briefly, $10 \mu \mathrm{L}$ of live HSV-1 (Wall strain at $1 \times 10^{5}$ plaque-forming units) was placed on shaved ear pinna, the drop was spread out slightly on the skin with the shaft of a 24-gauge needle and 10 parallel scarifications were made with the sharp edge of the bevel through the inoculum fluid. In the latent model of infection, infected mice were nourished under normal conditions for 1 month and were culled to determine the presence of latent virus or virus titers or both in trigeminal ganglia as described next.

\section{Assays of latent infection in mice}

For assay of latent infection, trigeminal ganglia of latently infected mice were aseptically removed and transferred into $4 \mathrm{~mL}$ of MEM, which was supplemented with $5 \%$ FBS and penicillin/streptomycin/ fungizone, and were incubated at $37^{\circ} \mathrm{C}$ in $5 \% \mathrm{CO}_{2}$ for 5 days. The ganglia were individually homogenized in their culture medium and centrifuged at $2000 \mathrm{rpm}$ for $5 \mathrm{~min}$ to remove debris. Resulting supernatants were divided and either used to infect Vero cells prepared in 24-well plates as described earlier or assayed by quantitative polymerase chain reaction (PCR) for viral DNA. In the cell culture test, the wells were inspected daily for the evidence of virus-induced cytopathic effect for 10 days. The presence of cytopathic effect indicated that the ganglion was harboring the virus and was latently infected (36). For the quantitative PCR test, DNA was isolated from homogenates using the EZ1 Virus Mini Kit v2.0 (Qiagen, Hilden, Germany). Amplification, detection and quantitation of HSV DNA was carried out using the artus HSV-1/2 RG PCR Kit v1 in a Rotor-Gene Q per the manufacturer's instructions, and data analysis was done by Rotor-Gene Q software, version 1.7 (all Qiagen). HSV-1 viral loads for the test samples were presented by averaging the logarithms of the titers (copies $/ \mathrm{mL}$ ).

\section{Results}

Generation and functional assessment of murine bone marrow-derived DCs

Morphologically, bone marrow-derived DCs had typical shapes of mDCs such as cytoplasmic dendritic projections (Figure 1A), and immunophenotypically they expressed several DC-associated cell surface markers as determined by fluorescence-activated cell sorter analysis (Figure 1B,C). DC populations used in immunizations lacked CD45R, CD4 and CD8 but expressed high levels of CD11c $(82.7 \%)$, MHC II (58.1\%), CD80 (89.3\%) and CD86 (28.3\%), typical features of $\mathrm{mDC}$ markers.

To assess the functionality of DCs, we used FITC-labeled antigen uptake assay as described earlier and found that iDCs, as opposed to mDCs, take up FITC-labeled dextran highly efficiently (Figure 2). iDCs generated on day 6 in the presence of GM-CSF and IL- 4 were highly capable of antigen uptake $(80.9 \%)$, whereas DCs produced on maturation of iDCs with TNF- $\alpha$ were not as efficient $(29.8 \%)$. The endocytic capacity of iDCs was investigated further by fluorescence microscopy using FITC-labeled Staphylococcus aureus particles, and the results showed that iDCs generated under the conditions described were highly competent in capturing foreign particles (data not shown).

\section{$D C / H S V-1$ vaccine induces protection against acute $H S V-1$ infection}

DCs generated in our study with features with regard to morphology, antigen uptake efficiency and relevant surface antigen expressions such as CD11c, MHC II and co-stimulatory markers of CD80 and CD86 were loaded with partially purified HSV-1 antigens as described earlier to obtain DC/HSV-1 vaccine. The vaccine containing $5 \times 10^{5} \mathrm{mDCs}$ per dosage was administered twice, 7 days apart, to $\mathrm{Balb} / \mathrm{c}$ mice via subcutaneous, intraperitoneal and intramuscular routes. Control groups received either DCs given subcutaneously at similar numbers but loaded with Vero cell extract (negative control) HSV$1 / \mathrm{ALH}$ prepared as described earlier.

Serum samples were analyzed 2 weeks after the last vaccination for HSV-1-specific antibodies using a sensitive ELISA procedure. As shown in Figure 3, subcutaneous vaccination with mock DC preparation induced undetectable anti-HSV-1 antibody response, whereas HSV-1/ALH vaccination elicited, as expected, high titers of HSV-1-specific IgG response. However, regardless of the route it was given, the DC/ HSV-1 vaccine induced an anti-HSV-1 antibody response that was comparable to the mock DC vaccine $(P>0.5)$ but markedly less than the HSV-1/ALH vaccination $(P<0.05)$, indicating that $B$-cell responses were not stimulated as efficiently as when HSV-1 antigens were given together with alum adjuvant.

We wanted to find out if $\mathrm{DC} / \mathrm{HSV}-1$ vaccine could induce protective immunity to an acute lethal infection challenge despite the fact that it did not 


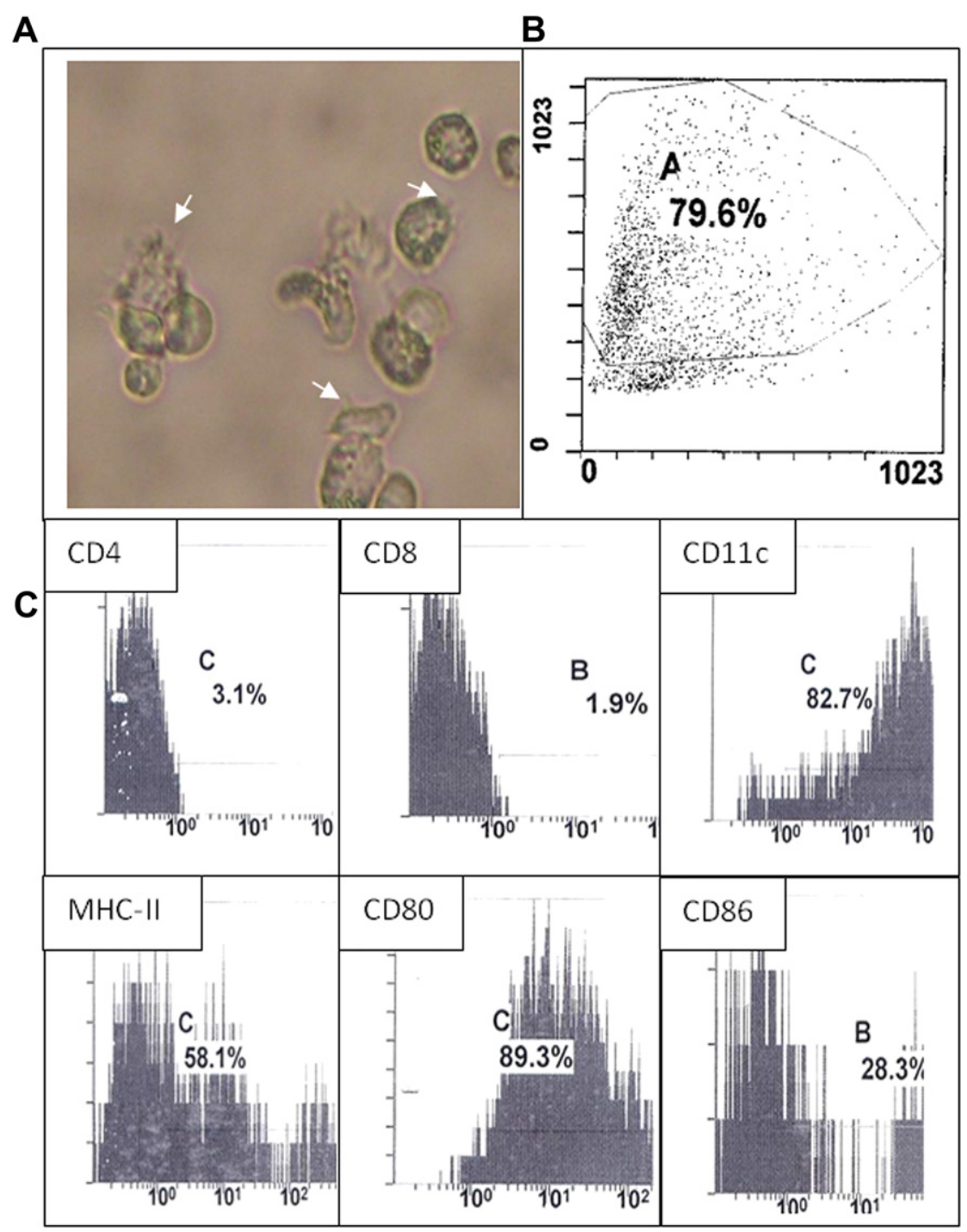

Figure 1. Microscopy and immunophenotype of bone marrow-derived mononuclear cells cultured in the presence of GM-CSF and IL-4 for 6 days followed by 1 more day of culturing for maturation with TNF- $\alpha$. (A) DCs show distinct membrane outgrowths (white arrows). (B) Representative fluorescence-activated cell sorter histogram of the gated large and granular cell population. (C) Expression percentages of CD4, CD8, CD11c, MHC II, CD80 and CD86 surface markers.

elicit a strong anti-HSV-1 antibody response. Mice vaccinated with two dosages 1 week apart of the DC/ HSV-1 vaccine and control vaccines (mock DC and HSV-1/ALH) were challenged 7 days later with a lethal dose of HSV-1. In this acute infection model, naïve mice die of severe HSV-1 infection over 10-15 days. In our challenge study, mice in the control group vaccinated with mock DCs were lost on challenge with live HSV-1, whereas $60 \%$ of mice in the group receiving HSV-1/ALH vaccine survived (Figure 4). However, the degree of protection afforded by DC/HSV-1 varied; subcutaneous and intraperitoneal administration of the vaccine endowed as much protection as the HSV-1/ALH vaccine, whereas vaccination via the intramuscular route resulted in $100 \%$ survival. We corroborated our findings with a repeat experiment, which suggested that the protection levels provided by the DC/HSV-1 vaccines given subcutaneously or intraperitoneally were not statistically significant compared with the survival rate obtained with HSV-1/ALH vaccination $(P>0.05)$. Although the difference between the administration routes of the DC/HSV-1 vaccine was evident only for intramuscular injection in regard to survival rates, the DC/HSV-1 vaccine, which afforded complete protection against lethal challenge with live virus, was not effective enough to induce anti-HSV-1 IgG response in mice. In other words, mice responding to HSV-1/ALH vaccination with high levels of antiHSV-1 antibody were not protected, albeit statistically not significant, as efficiently as the mice receiving the DC/HSV-1 vaccine intramuscularly, indicating 


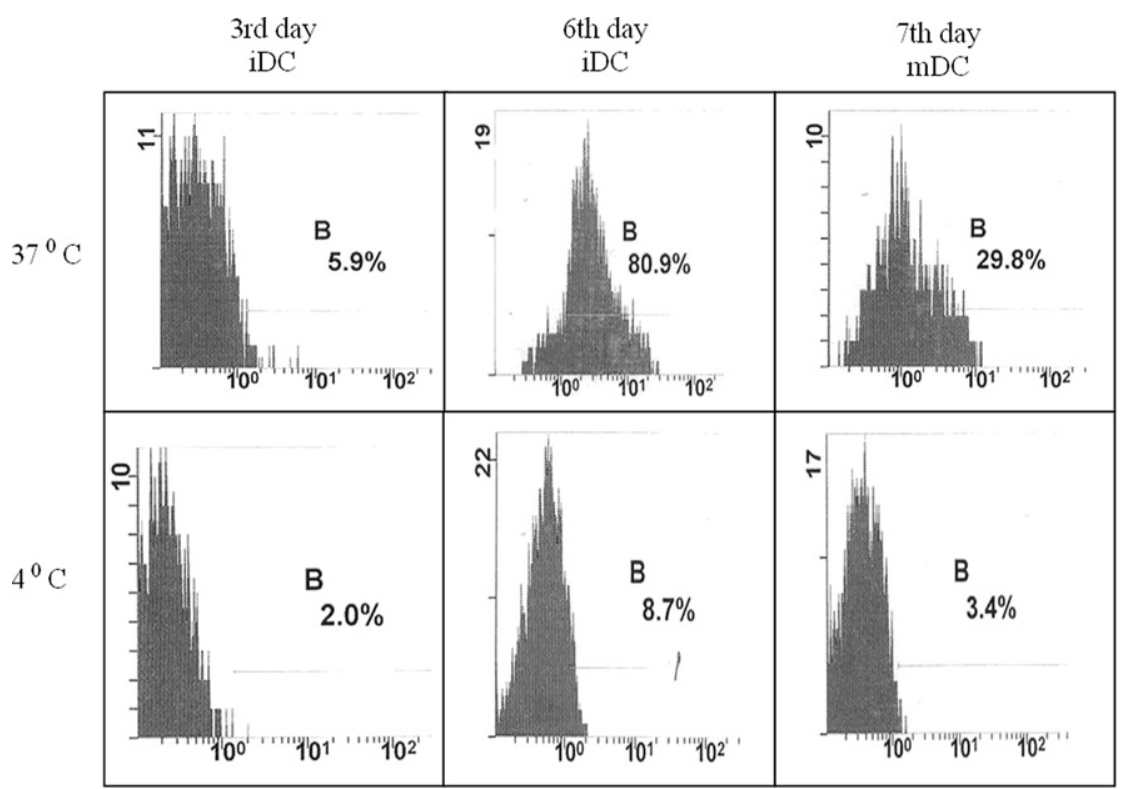

Figure 2. Flow cytometry analysis of the antigen uptake capacity of DCs at various time points of culture. Cells on the 3rd day culture show insignificant antigen uptake, whereas DCs generated on the 6th day are in an immature state (iDC) and are highly efficient in antigen uptake compared with TNF- $\alpha$ matured DCs (mDC), which are expected to show less ability with respect to antigen capturing activity.

that antibody levels were not strictly correlated with protection.

\section{DC/HSV-1 vaccine induces protection against establishment of latent $H S V-1$ infection}

The hallmark of HSV is that after infection of epithelial cells on the skin and mucosal surface, the virus enters the sensory nerve endings and travels via retrograde transport along nerve axons to the dorsal root ganglia where latency is established. One of the main goals of a HSV vaccine has been to prevent the establishment of latent infection.

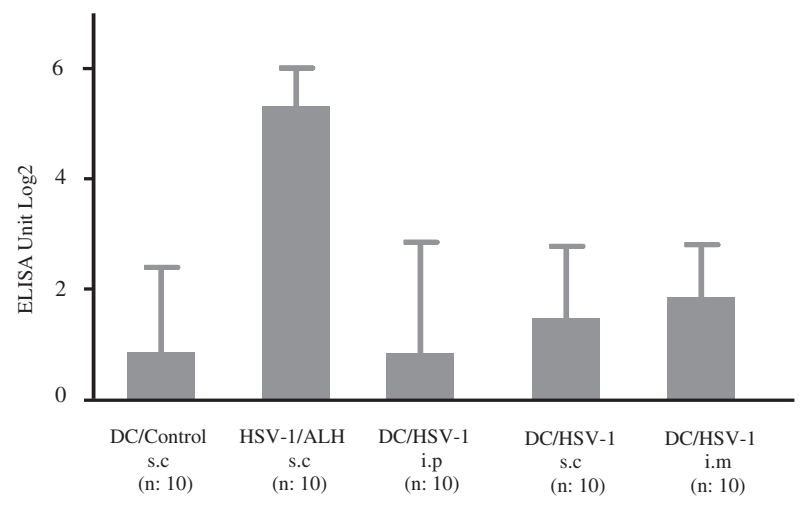

Figure 3. Levels of anti-HSV-1 antibody responses in groups of mice immunized via the subcutaneous (s.c) route with HSV-1/ $\mathrm{ALH}$ and with DC/control vaccine or with HSV-1 DC/HSV-1 vaccine given via subcutaneous (s.c), intraperitoneal (i.p) and intramuscular (i.m) routes. ELISA antibody levels are expressed as $\log ^{2}$ values $( \pm$ SEM).
In our study, because the DC/HSV-1 vaccine conferred complete protection in the lethal infection model, we wanted to test if $\mathrm{DC} / \mathrm{HSV}-1$ vaccine could also protect mice from the establishment of latent infection. To this end, in a single study, mice were first given two doses, as described earlier, of DC/ HSV-1, mock DCs and HSV-1/ALH intramuscularly and challenged with live HSV-1 after 7 days percutaneously via one ear as described earlier to allow establishment of the latent infection in trigeminal ganglia. After 1 month of nourishing of the infected mice, trigeminal ganglia were processed

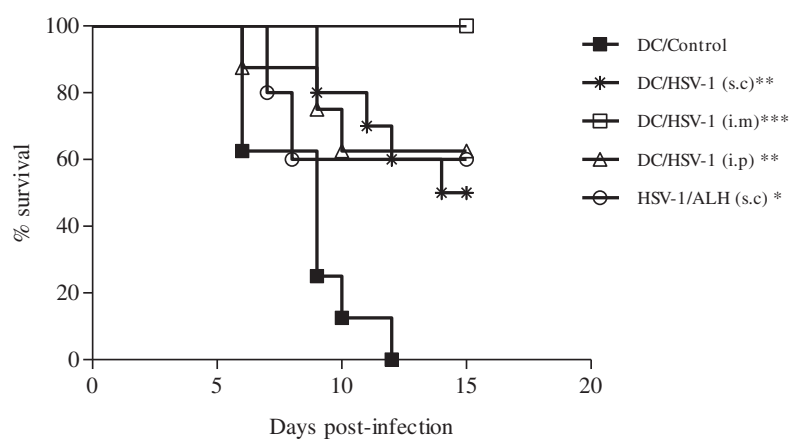

Figure 4. Protection of mice from acute or lethal HSV-1 infection by vaccination via the subcutaneous (s.c) $(\mathrm{n}=10)$ route with HSV-1/ALH and with DC/control vaccine $(\mathrm{n}=8)$ or with HSV-1 DC/HSV-1 vaccine given via subcutaneous (s.c) $(n=10)$, intraperitoneal (i.p) $(\mathrm{n}=8)$ and intramuscular (i.m) $(\mathrm{n}=10)$ routes. Survival rates were estimated according to the Kaplan-Meier method and were compared using the log-rank test (Cox-Mantel using GraphPad Prism [GraphPad Software, San Diego, CA, USA]). ${ }^{*} P<0.05 ; * * P<0.01 ; * * P<0.001$. 
Table I. Incidence of latent infection in trigeminal ganglia following inoculation ${ }^{\mathrm{a}}$ by scarification of the ear pinna in mice immunized intramuscularly with DC/HSV-1, HSV-1/ALH and $\mathrm{DC} /$ control vaccines.

\begin{tabular}{|c|c|c|}
\hline \multirow[b]{2}{*}{$\begin{array}{l}\text { Immunizing } \\
\text { materials }\end{array}$} & \multicolumn{2}{|c|}{ Assay of latent infection in ganglia } \\
\hline & $\begin{array}{l}\text { By cell culture test }{ }^{\mathrm{b}} \\
\text { (number of positive } \\
\text { samples/number of } \\
\text { mice tested) }\end{array}$ & $\begin{array}{c}\text { By quantitative PCR test } \\
\log _{10}(\text { mean } \pm \text { SEM })^{c} \\
\text { (number of positive } \\
\text { samples/number of } \\
\text { mice tested) }\end{array}$ \\
\hline DC/control & $5 / 8$ & $5.8 \pm 0.3(5 / 8)$ \\
\hline DC/HSV-1 & $0 / 7^{\mathrm{d}}$ & $<0.9 \pm 0.2(0 / 7)$ \\
\hline HSV-1/ALH & $2 / 6^{\mathrm{e}}$ & $4.6 \pm 0.4(2 / 6)$ \\
\hline
\end{tabular}

$P$ values calculated by Fisher exact test.

${ }^{a}$ Challenged via ear pinna with $10^{5}$ plaque-forming units HSV-1 (strain Wall) 7 days after second immunization.

${ }^{\mathrm{b}}$ Trigeminal ganglia cultivated for 5 days were homogenized and seeded onto host cells, or used in quantitative PCR test as described in the methods section.

${ }^{\mathrm{c} C a l c u l a t e d}$ by averaging the logarithms of the titers (copies $/ \mathrm{mL}$ ). ${ }^{\mathrm{d}} P<0.05$ compared with $\mathrm{DC} /$ control group.

${ }^{\mathrm{e}} \mathrm{P}>0.05$ compared with DC/HSV-1 and DC/control group.

as described in the methods section. As summarized in Table I, the results of both the cell culture testing of live virus in ganglion homogenates and the realtime PCR quantification test showed that vaccination of mice with DC/HSV-1 could also induce $100 \%$ protection as reflected by the absence of virus in trigeminal ganglia indicating that the vaccine was able to arrest the virus at the entry site or prevent traveling to the trigeminal ganglia.

Compared with the DC/HSV-1 vaccine, the HSV-1/ALH vaccine and the mock DC preparation were markedly less efficient in preventing the establishment of latency. Of eight mice, two vaccinated with the HSV-1/ALH vaccine and five vaccinated with the mock DC preparation were latently infected (Table I). Although the level of protection from the establishment of viral latency by $\mathrm{DC} / \mathrm{HSV}-1$ vaccination was significantly higher $(P=0.0256)$ than the rate of latency seen in the mock DC vaccination group (five mice positive for virus out of eight), this high level of protection achieved with the DC/HSV-1 vaccine should be interpreted with some caution. Not only was there no statistically significant difference between the DC/HSV-1 and HSV-1/ALH vaccines $(P>0.05)$, but also no repeat experiment was performed to confirm the findings.

\section{Discussion}

The salient feature of the present study is that DCs loaded with protein antigens induce a variable immune response in regard to generation of antigenspecific antibody and protection in a host, at least in the model employed here. This conclusion was based mainly on the findings that HSV-1-loaded DCs conferred protection against live virus challenge despite the fact that they were not as efficient as HSV$1 / \mathrm{ALH}$ in eliciting virus-specific antibody response. It was shown that immune response in regard to protection was more pronounced if antigen-loaded DCs were administered intramuscularly as opposed to subcutaneously or intraperitoneally. Our results may have some implications in design and use of antigen-loaded DC vaccines not only for infectious diseases but also for anti-cancer studies. DCs are intensely tested in cancer studies, and the issues relating to design and use of DC vaccines have been the subject of discussions in several reports (37-39). In several experimental and clinical studies, antigenloaded DCs were usually administered via subcutaneous, intravenous, intranodal or intradermal routes (38). Although the administration routes were not compared, it has been shown in some reports that DCs loaded with HCV core protein administered by the intramuscular and intraperitoneal routes induced a strong cytotoxic T-cell response $(40,41)$. It appears that inherent problems (i.e., administration route, number of injections, type of antigen, number of cells) in using DC vaccines are also valid in the case of DC vaccines targeted for infectious agents.

In regard to HSV, it is known that administration of viral proteins, at least together with different adjuvants in various amounts and via different routes, has a major impact on generating a protective immune response (31). However, the issue of which type of immune response induces better protection against challenge is controversial. The relationship between higher antibody levels and protection obtained by active or passive immunization has been supported in more recent studies $(11,42-45)$ as well as previous studies $(29,46-48)$. Several reports suggest that HSV-specific antibodies do not always confer protection (49-53); this is also true for latently infected individuals in whom the presence of circulating high levels of specific antibodies, even if they are of the neutralizing type, does not correlate with protection suggesting that antibody to the virus may be useless (54).

As shown in our study, although the HSV-1/ALH vaccine induced significantly high levels of antiHSV-1 antibody response, it was markedly less efficient than the DC/HSV-1 vaccine, which induced an antibody response comparable to the mock DC vaccine but was highly potent in protection against virus challenge. Other studies also demonstrated that DC vaccines prepared by virus or virus proteins do not induce high levels of antibody response $(10,41)$. However, a single study reported that DCs loaded with $\mathrm{gB} / \mathrm{gD}$ proteins of $\mathrm{HSV}-2$ induced high levels of specific antibody response, but the observed 
protection was attributed to the role of $\mathrm{CD}^{+}$ cells and IFN- $\gamma$ cytokine response (11). For HSV infection, it has been argued that $\mathrm{CD} 4^{+}$and $\mathrm{CD} 8^{+}$ $\mathrm{T}$-cell responses are more essential than antibody response (including the neutralization type) for the prevention of primary and latent infections $(55,56)$. In a more recent study, it was shown that $\mathrm{CD} 4^{+} \mathrm{T}$ cell-mediated viral clearance was relatively more important in preventing primary and latent infections (57). After activation by local tissue-resident DCs, $\mathrm{T}_{\mathrm{H}} 1$ cells were reported to mediate antiviral protection through local secretion of IFN- $\gamma$ rather than FasL or perforin related direct lysis (58). One of our findings suggests that despite eliciting an insignificant anti-HSV-1 antibody response, the high level of protection conferred by the DC/HSV-1 vaccine could be attributed to induction of a $\mathrm{CD} 4^{+} \mathrm{T}$ cellmediated immune response. As mentioned before, vaccination of mice with $\mathrm{HSV}-2 \mathrm{gB} / \mathrm{gD}$-loaded DCs was reported to protect mice against intravaginal live HSV-2 challenge through $\mathrm{CD} 4^{+} \mathrm{T}$-cell response that relied on IFN- $\gamma$ secretion (11).

One of the main goals of developing HSV vaccines has been to produce an optimal immunity that can prevent establishment of latent infection or decrease HSV reactivation from latency or decrease virus replication after a reactivation event. Various experimental models have shown that prevention of latent infection to some extent is possible $(31,34,35,59)$. In our study, using a completely different antigen presentation model, we observed that the level of protection from the establishment of viral latency by the DC/HSV-1 vaccine was significantly different than the rate of latency (five mice positive for virus out of eight) seen in the mock DC vaccine group. However, this high level of protection achieved with the DC/HSV-1 vaccine should be interpreted with some caution. There was no statistically significant difference between the DC/HSV-1 and HSV-1/ALH vaccines. Our results require further confirmation by repeat experiments using large numbers of animals.

In conclusion, efforts to design an effective vaccine against HSV-1 and HSV-2 have created a plethora of formulations among which attenuated live virus models, replication-defective HSV-1 vaccines, adjuvanted glycoprotein vaccine preparations and DNA vaccines have been assessed in experimental and clinical studies $(60,61)$. Despite the promising results of several candidate vaccines in animal studies, most clinical trials have been disappointing $(62,63)$, and further strategies are warranted in the pursuit of a potent HSV vaccine. The use of DCs in designing vaccines for both cancer and infectious diseases may provide better alternatives in this regard. Taken together, our findings obtained using DCs loaded with partially purified HSV-1 proteins may be relevant in future HSV vaccine formulations and in designing vaccines for infectious agents including HIV, HBV and HCV.

\section{Acknowledgments}

We are grateful to Dr. Z. Yazıcı for his critical reading of the manuscript and to Fatma Sumer and Seda Ocak for technical assistance. This work was supported by the Scientific and Technological Research Council of Turkey (TÜBİTAK, 108S022) and by the Research Foundation of Karadeniz Technical University.

Disclosure of interest: The authors have no commercial, proprietary, or financial interest in the products or companies described in this article.

\section{References}

1. Gilboa E. DC-based cancer vaccines. J Clin Invest. 2007;117: 1195-203.

2. Palucka K, Ueno H, Fay J, Banchereau J. Dendritic cells and immunity against cancer. J Intern Med. 2011;269:64-73.

3. Asim S, Sunil KC, Kartik M, Kenneth AF, Malaya BC. Dendritic cell based vaccines for immunotherapy of cancer. Cancer Ther. 2003;1:299-314.

4. Hatfield P, Merrick AE, West E, O'Donnell D, Selby P, Vile R, et al. Optimization of dendritic cell loading with tumor cell lysates for cancer immunotherapy. J Immunother. 2008; 31:620-32.

5. Fry TJ, Shand JL, Miliron M, Tasian SK, Mackall CL. Antigen loading of DCs with irradiated apoptotic tumor cells induces improved anti-tumor immunity compared to other approaches. Cancer Immunol Immunother. 2009;58:1257-64.

6. Ralph MS, Jacques B. Taking dendritic cells into medicine. Nature. 2007;449:419-26.

7. Stefano MS, Filippo B. Advances in the use of dendritic cells and new adjuvants for the development of therapeutic vaccines. Stem Cells. 2003;21:495-505.

8. Mbow ML, Zeidner N, Panella N, Titus RG, Piesman J. Borrelia burgdorferi pulsed dendritic cells induce a protective immune response against tick-transmitted spirochetes. Infect Immun. 1997;65:3386-90.

9. Ludewig B, Ehl U, Karrer B, Odermatt H, Hengartner S, Zinkernagel RM. Dendritic cells efficiently induce protective antiviral immunity. J Virol. 1998;72:3812-8.

10. Lopez CB, Fernandez A, Sesma A, Czelusniak SM, Schulman JM, Moran TM. A mouse model for immunization with ex vivo virus-infected dendritic cells. Cellular Immunol. 2000;206:107-15.

11. Schön E, Harandi AM, Nordström I, Holmgren J, Eriksson K. Dendritic cell vaccination protects mice against lethality caused by genital herpes simplex virus type 2 infection. J Reprod Immunol. 2001;50:87-104.

12. Silvia B, Katia P, Claudia M, Roberta G, Silvia B, Emanuela B, et al. A dendritic cell vaccine against invasive aspergillosis in allogeneic hematopoietic transplantation. Blood J. 2003;102:3807-14.

13. Hua S, Ronald M, William W, Elizabeth F, John CP, Harlan DC. Vaccination against chlamydial genital tract 
infection after immunization with dendritic cells pulsed ex vivo with nonviable Chlamydiae. J Exp Med. 1998;188:809-18.

14. Ozawa Y, Suda T, Nagata T, Hashimoto D, Nakamura $Y$, Enomoto N, et al. Mucosal vaccine using CTL epitope-pulsed dendritic cell confers protection for intracellular pathogen. Am J Respir Cell Mol Biol. 2009;41:440-8.

15. Catherine I, Kris C. DNA vaccines: designing strategies against parasitic infections. Genet Vaccines and Ther. 2004;2: $17-24$.

16. Lu W, Arraes LC, Ferreira WT, Andrieu JM. Therapeutic dendritic-cell vaccine for chronic HIV-1 infection. Nat Med. 2004;10:1359-65.

17. Zabaleta A, Llopiz D, Arribillaga L, Silva L, Riezu-Boj JI, Lasarte JJ, et al. Vaccination against hepatitis $\mathrm{C}$ virus with dendritic cells transduced with adenovirus encoding NS3 protein. Mol Ther. 2008;16:210-7.

18. García F, Lejeune M, Climent N, Gil C, Alcami J, Morente V, et al. Therapeutic immunization with dendritic cells loaded with heat-inactivated autologous HIV-1 in patients with chronic HIV-1 infection. J Infect Dis. 2005;191:1680-5.

19. Ide F, Nakamura $T$, Tomizawa M, Kawana-Tachikawa A, Odawara T, Hosoya N, et al. Peptide-loaded dendritic-cell vaccination followed by treatment interruption for chronic HIV-1 infection: a phase 1 trial. J Med Virol. 2006;78:711-8.

20. Connolly NC, Whiteside TL, Wilson C, Kondragunta V, Rinaldo CR, Riddler SA. Therapeutic immunization with HIV-1 peptide-loaded dendritic cells is safe and immunogenic in HIV. Clin Vaccine Immunol. 2008;15:284-92.

21. Lasarte JJ, Garcia-Granero M, Lopez A, Casares N, Garcia N, Civeira M-P, et al. Cellular immunity to hepatitis $C$ virus core protein and the response to interferon in patients with chronic hepatitis C. Hepatology. 1998;2:815-22.

22. Gowans EJ, Jones KL, Bharadwaj M, Jackson DC. Prospects for dendritic cell vaccination in persistent infection with hepatitis C virus. J Clin Virol. 2004;30:283-90.

23. Encke J, Findeklee J, Geib J, Pfaff E, Stremmel W. Prophylactic and therapeutic vaccination with dendritic cells against hepatitis C virus infection. Clin Exp Immunol. 2005;142: 362-9.

24. Zabaleta A, Arribillaga L, Llopiz D, Dotor J, Lasarte JJ, Prieto J, et al. Induction of potent and long-lasting CD4 and CD8 T-cell responses against hepatitis $\mathrm{C}$ virus by immunization with viral antigens plus poly(I: C) and anti-CD40. Antiviral Res. 2007;74:25-35.

25. Beckebaum S, Cicinnati VR, Zhang X, Ferencik S, Frilling A, Grosse-Wilde $\mathrm{H}$, et al. Hepatitis B virus-induced defect of monocyte-derived dendritic cells leads to impaired $\mathrm{T}$ helper type 1 response in vitro: mechanisms for viral immune escape. Immunology. 2003;109:487-95.

26. Tavakoli S, Schwerin W, Rohwer A, Hoffmann S, Weyer S, Weth $R$, et al. Phenotype and function of monocyte derived dendritic cells in chronic hepatitis B virus infection. J Gen Virol. 2004;85:2829-36.

27. Akbar F, Furukawa S, Onji M, Murata Y, Niya T, Kanno S, et al. Safety and efficacy of hepatitis B surface antigen-pulsed dendritic cells in human volunteers. Hepatol Res. 2004;29: 136-41.

28. Chen M, Li YG, Zhang D, Wang ZY, Zeng WQ, Shi XF, et al. Therapeutic effect of autologous dendritic cell vaccine on patients with chronic hepatitis B: a clinical study. World J Gastroenterol. 2005;11:1806-8.

29. Erturk M, Welch MJ, Phillpotts RJ, Jennings R. Protection and serum antibody responses in guinea-pigs and mice immunized with HSV-1 antigen preparations obtained using different detergents. Vaccine. 1989;7:431-6.

30. Shi M, Qian S, Chen WW, Zhang H, Tang Zhang Z, et al. Hepatitis $B$ virus (HBV) antigen-pulsed monocyte-derived dendritic cells from HBV-associated hepatocellular carcinoma patients significantly enhance specific $\mathrm{T}$ cell responses in vitro. Clin Exp Immunol. 2006;147:277-86.

31. Erturk M, Hill TJ, Shimeld C, Jennings R. Acute and latent infection of mice immunized with HSV-1 ISCOM vaccine. Arch Virol. 1992;125:87-101.

32. Jennings R, Erturk M. Comparative studies of HSV-1 antigens solubilised from infected cells by using non-ionic or zwitterionic detergents. J Med Virol. 1990;31:98-108.

33. Lutz MB, Kukutsch N, Ogilvie AL, Robner S, Koch K, Romani N, et al. An advanced culture method for generating large quantities of highly pure dendritic cells from mouse bone marrow. J Immunol Methods. 1999;223:77-92.

34. Al-Ghamdi A, Jennings R, Bentley H, Potter CW. Latent HSV-1 infection in mice immunized with a zwitterionic detergent-extracted HSV-1 antigen preparation. ArchVirol. 1989;108:19-31.

35. Lin WR, Jennings R, Smith TL, Wozniak MA, Itzhaki RF. Vaccination prevents latent HSV1 infection of mouse brain. Neurobiol Aging. 2001;22:699-703.

36. Harbour DA, Hill TJ, Blyth WA. Recurrent herpes simplex in the mouse: inflammation in the skin and activation of virus in the ganglia following peripheral stimulation. J Gen Virol. 1983;64:1491-8.

37. Mullins DW, Sheasley SL, Ream RM, Bullock TN, Fu YX, Engelhard VH. Route of immunization with peptide-pulsed dendritic cells controls the distribution of memory and effector $\mathrm{T}$ cells in lymphoid tissues and determines the pattern of regional tumor control. J Exp Med. 2003;198:1023-34.

38. Gosse JA. Migration of dendritic cell based cancer vaccines: in vivo veritas. Curr Opin Immunol. 2005;17:170-4.

39. Barrat-Boyes SM, Figdor CG. Current issues in delivering DCs for immunotherapy. Cytotherapy. 2004;6:105-10.

40. Moriya O, Matsui M, Osorio M, Miyazawa H, Rice CM, Feinstone SM, et al. Induction of hepatitis $C$ virus-specific cytotoxic $\mathrm{T}$ lymphocytes in mice by immunization with dendritic cells treated with an anthrax toxin fusion protein. Vaccine. 2001;20:789-96.

41. Yu H, Babiuk LA, van Drunen Littel-van den Hurk S. Strategies for loading dendritic cells with hepatitis C NS5a antigen and inducing protective immunity. J Viral Hepatol. 2008; 15:459-70.

42. Richards CM, Case R, Hirst TR, Hill TJ, Williams NA. Protection against recurrent ocular herpes simplex virus type 1 disease after therapeutic vaccination of latently infected mice. J Virol. 2003;77:6692-9.

43. Quenelle DC, Collins DJ, Marciani DJ, Kern ER. Effect of immunization with herpes simplex virus type-1 (HSV-1) glycoprotein D (gD) plus the immune enhancer GPI-0100 on infection with HSV-1 or HSV-2. Vaccine. 2006;24:1515-22.

44. Ghaemi A, Soleimanjahi H, Bamdad T, Soudi S, Arefeian E, Hashemi SM, et al. Induction of humoral and cellular immunity against latent HSV-1 infections by DNA immunization in BALB/c mice. Microbiol Infect Dis. 2007;30:197-210.

45. Brans R, Akhrameyeva NV, Yao F. Prevention of genital herpes simplex virus type 1 and 2 disease in mice immunized with a gD-expressing dominant-negative recombinant HSV-1 . J Invest Dermatol. 2009;129:2470-9.

46. Hilfenhaus J, Moser H, Herrmann S, Mauller R. Herpes virus subunit vaccine: characterization of the virus strain used and testing of the vaccine. Dev Biol Stand. 1982;52:321-5.

47. Kumel G, Kaerner HC, Levine M, Schroder CH, Glorioso JC. Passive immunoprotection by HSV specific monoclonal antibodies and monoclonal antibody resistant mutants altered in pathogenicity. J Virol. 1985;7:333-7.

48. Berman PW, Vogt PE, Gregory T, Lansky LA, Kern ER. Efficacy of recombinant glycoprotein $\mathrm{D}$ subunit vaccines on 
the development of primary, recurrent and latent genital infections with herpes simplex virus type 2 in guinea-pigs. J Infect Dis. 1988;157:897-902.

49. Watari E, Dietzschold B, Szokan G, Heber-Katz E. A synthetic peptide induces long-term protection from lethal infection with herpes simplex virus 2. J Exp Med. 1987;165:459-70.

50. Kuklin NA, Daheshia M, Chun S, Rouse BT. Role of mucosal immunity in herpes simplex virus infection. J Immunol. 1998; 160:5998-6003.

51. Milligan GN, Bernstein DI, Bourne N. T lymphocytes are required for protection of the vaginal mucosae and sensory ganglia of immune mice against reinfection with herpes simplex virus type 2. J Immunol. 1998;160:6093-7000.

52. Stanberry LR. Clinical trials of prophylactic and therapeutic herpes simplex virus vaccines. Herpes. 2004;11(Suppl. 3): 161A-9A.

53. Simms JR, Heath AW, Jennings R. Use of herpes simplex virus (HSV) type 1 ISCOMS 703 vaccine for prophylactic and therapeutic treatment of primary and recurrent HSV-2 infection in guinea pigs. J Infect Dis. 2000;181:1240-8.

54. Davis-Poynter NJ, Farrell HE. Masters of deception: a review of herpesvirus immune evasion strategies. Immunol Cell Biol. 1996;74:513-22.

55. Ghiassi H, Perng G, Nesburn AB, Wechsler SL. Either a CD4+ or CD8+T cell function is sufficient for clearance of infectious virus from trigeminal ganglia and establishment of herpes simplex virus type 1 latency in mice. Microb Pathog. 1999;27:387-94.
56. Khanna KM, Lepisto AJ, Decman V, Hendricks RL. Immune control of herpes simplex virus during latency. Curr Opin Immunol. 2004;16:463-9.

57. Johnson AJ, Chu CF, Milligan GN. Effector CD4+ T-cell involvement in clearance of infectious herpes simplex virus type 1 from sensory ganglia and spinal cords. J Virol. 2008;82: 9678-88.

58. Iijima N, Linehan MM, Zamora M, Butkus D, Dunn R, Kehry MR, et al. Dendritic cells and B cells maximize mucosal Th1 memory response to herpes simplex virus. J Exp Med. 2008;205:3041-52.

59. Brittle EE, Wang F, Lubinski JM, Bunte RM, Friedman HM. A replication-competent, neuronal spread-defective, live attenuated herpes simplex virus type 1 vaccine. J Virol. 2008; 82:8431-41.

60. Arvin A, Campadelli-Fiume G, Mocarski E. Herpes simplex vaccines. In: Arvin A, Campadelli-Fiume G, Mocarski E, Moore PS, Roizman B, Whitley R, et al, editors. Human herpesviruses: biology, therapy, and immunoprophylaxis. Cambridge: Cambridge University Press; 2007.

61. Rupp R, Bernstein DI. The potential impact of a prophylactic herpes simplex vaccine. Expert Opin Emerg Drugs. 2008;13: $41-52$.

62. Johnston C, Koelle DM, Wald A. HSV-2: in pursuit of a vaccine. J Clin Invest. 2011;121:4600-9.

63. Robert B, Belshe MD, Peter A, Leone MD, David I, Bernstein MD, et al. Efficacy results of a trial of a herpes simplex vaccine. N Engl J Med. 2012;366:34-43. 